\title{
The Band-Aid Strip
}

\section{Charles Darr and Jonathan Fisher}

In term three of 2003, two researchers from the New Zealand Council for Educational Research spent four weeks working in a Year 7 classroom exploring how students dealt with learning experiences focused on the area of proportional reasoning. They designed a series of lessons that encouraged the students to talk about their methods and reason their way to an answer.

As well as providing data on the issues involved in teaching students to become proportional reasoners, the project also produced insights into how different forms of equipment can encourage students to apply and talk about their reasoning. One simple piece of equipment that proved to be very useful was the "band-aid" strip.

This article presents a brief explanation of proportional reasoning, provides a quick overview of the project, and then introduces the band-aid strip, with suggestions for integrating it into lessons when dealing with ideas involving fractions, decimals, and percentages.

\section{Proportional reasoning}

Proportional reasoning is not easy to define. Susan Lamon, an American researcher, describes it as "draw[ing] on a huge web of knowledge" (Lamon, 1999, p. 5). At its heart, however, is the ability to compare ratios or fractions and to predict or create equivalent ratios or equivalent fractions. Most critically, it involves being able to recognise and make use of the multiplicative relationship that a proportional situation entails.

Learning to use proportional reasoning takes time. However, evidence suggests that for most people it will not develop just through general experience and maturation. Instead, children need to be provided with a wide range of rich learning experiences involving critical components of proportional reasoning.

In New Zealand, most students have traditionally been introduced to proportional reasoning through problems involving fractions, decimals, and percentages. Later, the concept of ratio has been introduced. Unfortunately, students are often taught only to use algorithmic methods to deal with these important mathematical ideas. This can mean that students rely on rote methods, or attempt to apply primitive intuitive strategies to deal with proportional situations, rather than developing their understanding and reasoning about the underlying relationships.

Proportional reasoning is a vital form of mathematical reasoning in our world. Situations that operate according to proportional rules are common anywhere mathematics is applied. Moreover, becoming a proportional reasoner provides an important foundation for further learning in mathematics, especially in algebra.

The National Council of Teachers of Mathematics in the United States has this to say about proportional reasoning:

The ability to reason proportionally develops in students throughout grades 5-8. It is of such great importance that it merits whatever time and effort must be expended to assure its careful development (National Council of Teachers of Mathematics, 1989, p. 82).

\section{The project}

The project undertaken by the NZCER researchers involved designing lessons centred around mathematical problem challenges that were intended to elicit proportional reasoning. The topic of percentages was chosen as a starting point because of the rich contexts it evoked and because of the belief that students were often exposed to percentages in their daily lives.

During the project, the students were expected to work in pairs, small groups, and sometimes in whole class settings to solve problems, explain their methods, and convince others of their reasoning. 
The lessons were also designed so that students could make connections between mathematical content areas. The researchers found that ideas from measurement, geometry, probability, and statistics could easily be integrated into problems that asked students to apply proportional reasoning.

Throughout the unit, journaling was used by the students to record their own ideas and methods. This often entailed presenting students with a problem or scenario and asking them to write an explanation of their approach or solution. Students were encouraged to use pictures and diagrams whenever these were helpful. The journals provided a rich source of formative assessment, and were used to inform the lesson design process, as well as to give feedback to the students.

\section{Using equipment and the band-aid strip}

The project enabled the researchers to use different forms of equipment to support the learning experiences. As well as providing concrete tools to facilitate reasoning, the handson nature of the equipment was often found to be a motivating influence for students. During the unit, students used rulers, measuring flasks, calculators, cuisenaire rods, decimal pipes, fraction kits, spinners, shape blocks, and number fans. ${ }^{1}$ Students were also taught how to set up and use double number lines and ratio tables.

One piece of equipment that turned out to be very useful was called the band-aid strip. Adapted from the equipment described in an article by Peter Patilla, ${ }^{2}$ the band-aid strip consists of an oblong-shaped card (approximately $27 \mathrm{~cm}$ by $4 \mathrm{~cm}$ ) that has been divided into ten equal parts, and a rubber band. The rubber band acts as a type of marker. It is stretched around the card with sufficient tension to prevent it from falling off, but is also loose enough to be moved up and down the length of the strip. By moving the marker along the card, students can use the strip to model different fractions, decimals, and percentages. A template for making the band-aid strip is given at the end of this article.

The band-aid strip turned out to be an excellent piece of equipment for "show me" activities. "Show me" activities ask students to hold up a simple piece of equipment to respond to a question, rather than putting up their hand, or calling out an answer. This allows the teacher to quickly scan all the students to assess understanding, instead of just hearing the answers from a few eager respondents. Hands and fingers can also be used as a "show me" device.

During the project, the band-aid strip was often used at the beginning of a lesson to get students thinking or to explore an idea. The band-aid strip allowed for some particularly rich activities involving proportional reasoning, especially when working with fractions, decimals, and percentages. As well as providing students with a way to display their answers, it also acted as a kind of scaffold to support their reasoning. By positioning the rubber band along the length of the strip, students could visually estimate different fractions, percentages, and decimals. Moreover, the ten marked sections provided benchmarks they could use to identify the exact positions of different proportions of the whole strip.

\section{Using the band-aid strips}

The strips can be used with a group of students or the whole class. It is probably best to concentrate on one or two ideas at a time. Before the students are asked any questions, the teacher should point out that the strip is like a part of the number line, or a percentage scale from 0 percent to 100 percent. When the marker is at the bottom, the number represented is zero (or 0 percent). When it is at the top, the number represented is one (or 100 percent).

When students have displayed their answer to a question, volunteers can be selected to explain why they have put the marker where it is. Alternatively, students can be asked to explain this to a partner.

\section{Questions that can be used with the strips}

\section{Finding fractions,} decimals, and percentages

The children can be asked to position the marker to show different fractions, percentages, and decimals. For instance:

Show me a half.

Show me a quarter.

Show me one-tenth, twotenths, etc.

Show me 10 percent, show me 20 percent, etc.

Show me 0.1 .

Students can find 0.1 hard to show the first time around, often pointing to 0.01 instead. The switch from fractions and percentages to decimals appears to be quite demanding.

The questions also become a little harder when the fractions, percentages, or decimals are less easily associated with tenths. For instance:

Show me 5 percent.

Show me two-fifths.

Show me a twentieth.

Here students can use the tenth markings to help them find equivalent fractions. For example, if each section represents a tenth, then two sections will represent a fifth. Therefore four sections, which is four-tenths, will represent two-fifths.

Students might notice that the symmetry of the strip means that it can be flipped to show what part of the card is left over. For instance, ask the students to show 70 percent. Then ask them to show 30 percent. Some of them will immediately flip it upside down, while others laboriously move the marker to its new position. Ask the children turning it upside down why they were able to do that.

\section{Comparisons}

The strip can also be used to answer comparison questions involving fractions, decimals, and percentages. For instance:

- Show me which is smaller, 0.5 or 0.75 .

- Show me which is bigger, 25 percent or 0.3.

- Show me which is bigger, 0.3 or two-fifths.

- Show me which is smaller, one-twentieth or 5 percent.

Comparing activities with the strips can also be done in the form of a group competition. First a range of fractions, decimals, and/or percentages is presented to the class. Each group then tries to organise its members to show the numbers in order, from smallest to largest. Each group member is responsible for showing one number. A group indicates that it is ready by sitting down and holding up the strips in order. Results are checked by asking the groups to say the numbers in order. This activity provides an excellent context for discussion and negotiation.

To start with, a list of decimals might prove a good challenge. 
THE BAND-AID STRIP

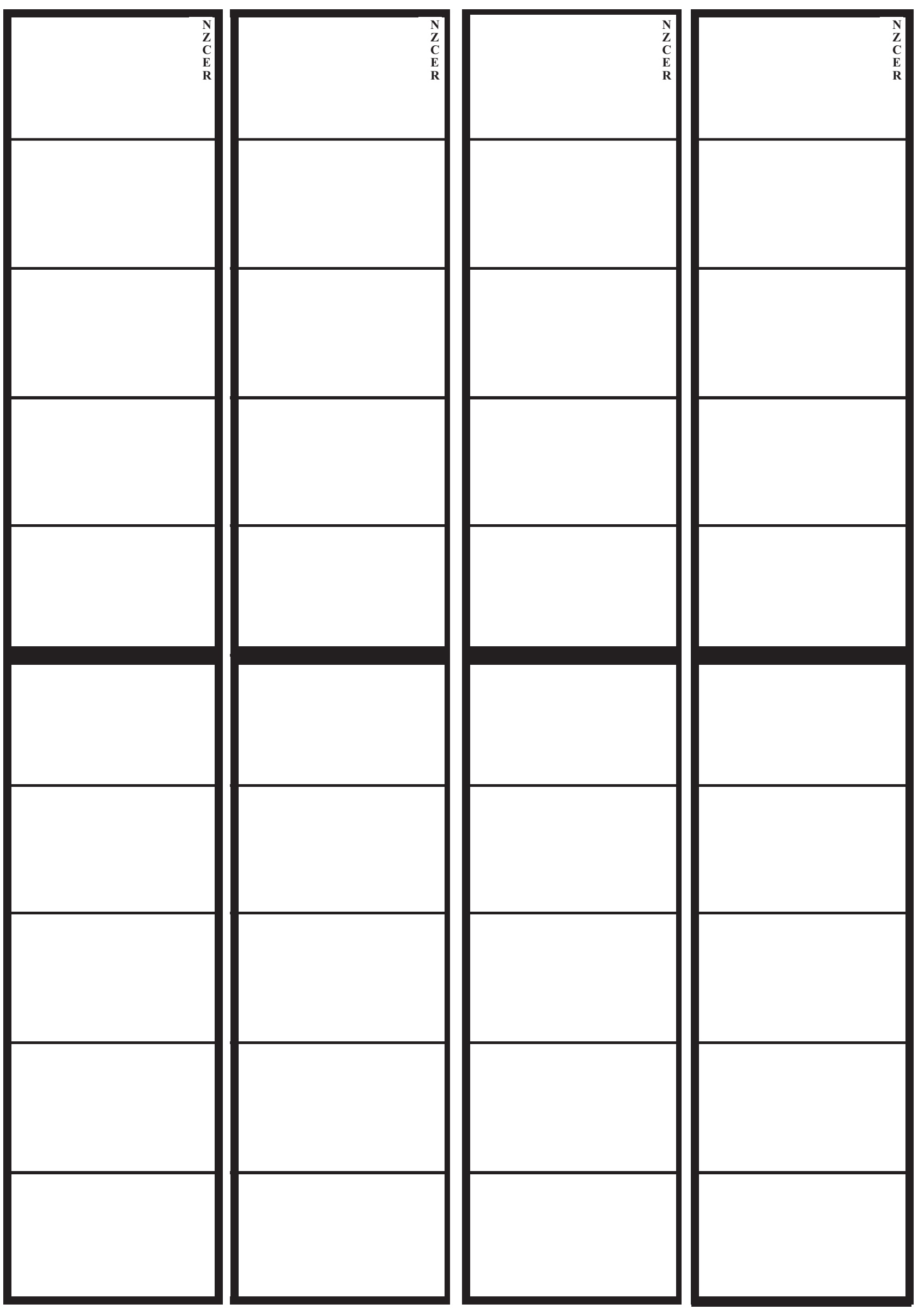


Later, the list might involve a mixture of fractions, decimals, and percentages. An example of some numbers to put in order is:

0.4, 45 percent, $5 / 20,0.8,95 / 100$.

The degree of difficulty depends on the fractions, decimals, and percentages used, and the extent to which they have been mixed up.

\section{Estimating (size of fractions and equivalence)}

Students can be asked to estimate where more difficult fractions, decimals, or percentages should be indicated on the strip. Students can become very proficient at estimating by eye, but they should also be encouraged to explain why their estimate is a good one. For instance, if the question was: "Estimate where 1/11 would be," a reasoned argument might suggest that the mark would be below the 1/10 mark, as elevenths are smaller than tenths.

Similarly, "Estimate where 8/9 would be," could be explained by reasoning that since ninths are larger than tenths, $8 / 9$ would be slightly further away from the top than $9 / 10$, which is exactly $1 / 10$ away.

\section{Probability}

The cards can also be used by students to model probabilities. Ask them questions such as:

- Show me how likely you think it is to rain today. What percentage is this?

- Show me what chance there is of getting a head when a single coin is tossed.

The cards can be used to help students think about the words that are often used to describe probabilities. For instance:

- If someone told you it was unlikely that Ireland would win the World Cup, show me how much chance you think they mean Ireland has.

- If there is a very good chance of rain tomorrow, show me what probability there is.

\section{Conclusion}

Learning how to reason proportionally is an important goal for students in mathematics. The experiences of the researchers in this project indicate that students can begin to apply this kind of reasoning when solving problems involving fractions, decimals, and percentages. Eliciting this kind of thinking, however, involves providing students with learning activities that promote thinking and discussion. Often,

Charles Darr works at NZCER as part of the Royal Society's

Mathematics, Science, and Technology Fellowship scheme.

Email: charles.darrळnzcer.org.nz

equipment can be used to help facilitate this.

The band-aid strip is one such piece of equipment. As well as providing students with a graphic tool to display their answers and help illustrate their methods, the strip allows them to reason about the relative sizes of fractions, and to make use of the important connections between fractions, decimals, and percentages. For the teacher, the band-aid strip can act as a valuable formative assessment tool, promoting dialogue and helping to make students' reasoning visible. It can help to construct the web of knowledge students will need to become proportional reasoners.

\section{References}

Lamon, S. J. (1999). Teaching fractions and ratios for understanding: Essential content knowledge and instructional strategies for teachers. Mahwah, NJ: Lawrebce Erlbaum Associates.

National Council of Teachers of Mathematics. (1989). Curriculum and evaluation standards for school mathematics. Reston, Va.: The Council.

Patilla, P. (1998). Interactive mental mathematics. Retrieved May 1, 2003, from

http://www-maths.mcs.st-andrews.ac.uk/ -smc/ journal/patilla.html.

\section{Notes}

1 A number fan is made up of a collection of digits, and sometimes a decimal point, which have been fastened together at the bottom. The fan allows students to select the digits they need to display numerical answers.

2 Found at www-maths.mcs.st-andrews.ac. uk/ smc/journal/patilla.html

A piece of "show me" equipment that has become popular in New Zealand classrooms through the numeracy projects is the number fan. This is made up of a collection of digits and sometimes, a decimal point, which have been fastened together at the bottom. The fan allows students to select the digits they need to display numerical answers. Hands and fingers can also be used as a "show me" device.

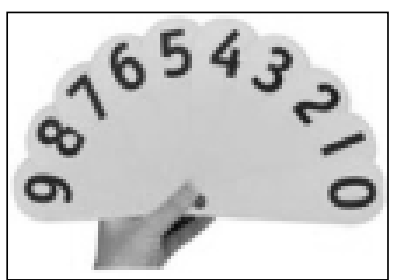

